\title{
ASSISTÊNCIA TÉCNICA E EXTENSÃO RURAL (ATER) NO TERRITÓRIO RURAL SERTÃO CENTRAL CABUGI E LITORAL NORTE (RN): O DESAFIO DA ADEQUAÇÃO SÓCIO-TÉCNICA
}

\author{
Emanoel Márcio Nunes ${ }^{1}$ \\ Mônica Soares $\mathrm{Cruz}^{2}$ \\ Vívian Menezes da Silva ${ }^{3}$
}

\begin{abstract}
RESUMO
O objetivo é analisar as ações de Assistência Técnica e Extensão Rural (ATER) no Território Rural Sertão Central Cabugi e Litoral Norte (RN), demonstrando as limitações de integração com o crédito e a organização coletiva, e evidenciando a necessidade da adequação sócio-técnica para 0 desenvolvimento rural. A metodologia utilizada foi a do "Diagrama de Venn", e a técnica utilizada foi a realização de visitas aos dez municípios que compõem o Território. Os resultados se basearam nos levantamentos e no roteiro de entrevistas com prestadores de ATER, associações e atores dos dez municípios do Território, que, de forma participativa, avaliaram as ações de ATER. Concluindo, percebe-se a necessidade de um modelo de ATER capaz de promover maior integração com o crédito e à organização coletiva e que incorpore mais as questões relacionadas com a adequação sóciotécnica.
\end{abstract}

Palavras-chave: ATER, desenvolvimento territorial, gestão, sustentabilidade.

\section{AGRICULTURAL EXTENSION (ATER) IN THE RURALTERRITORY SERTÃO CENTRAL CABUGI E LITORAL NORTE (RN): THE CHALLENGE OF SOCIO TECHNICAL ADEQUACY}

\begin{abstract}
The objective is to analyze the actions of Agricultural Extension (ATER) in the rural territory of Sertão Central Cabugi and Litoral Norte, Rio Grande do Norte state, Brazil, demonstrating the limitations of integration with rural credit and collective organization, and highlighting the need for socio-technical adequacy for the rural development. The methodology used was the "Venn Diagram", and the technique used was to carry out visits to the ten municipalities that make up the territory. The results were based on the surveys and the interview script with ATER providers, associations and actors from the ten municipalities in the territory, who, in a participatory way, evaluated the ATER actions. In conclusion, there is a need for an
\end{abstract}

\footnotetext{
${ }^{1}$ Graduado em Economia (UFRN). Mestrado em Economia (IE/UFU). Doutorado em Desenvolvimento Rural (PGDR/UFRGS). Professor dos Programas de Pós-Graduação em Economia (PPE/UERN) e em Planejamento e Dinâmicas Territoriais do Semiárido (PLANDITES/UERN).E-mail: emanoelnunes@uern.br

${ }^{2}$ Graduada em Economia (UFRN). Mestrado em Economia (UFRN). E-mail: monicasoares25@yahoo.com.br

${ }^{3}$ Graduada em Economia (UERN). Mestranda em Planejamento e Dinâmicas Territoriais do Semiárido (UERN). E-mail: menezesvivian123@gmail.com
} 
ATER model capable of greater integration with rural credit and collective organization and incorporate more issues related to socio-technical adequacy.

Keywords: Agricultural extension, territorial development, manager, sustainability.

\section{INTRODUÇÃO}

Um dos maiores desafios da agricultura familiar é tornar realidade a interação entre os pilares do tripé constituído pelo acesso ao crédito, organização coletiva e acompanhamento técnico. O não alinhamento entre esses três elementos tende a reduzir a capacidade tecnológica dos agricultores e limitar as possibilidades de dinamização no meio rural, além de reproduzir um ambiente com pouca estrutura e com atividades precárias. Isso reafirma a importância das ações de Assistência Técnica e Extensão Rural (ATER) no cotidiano dos agricultores familiares e suas organizações coletivas, para construir soluções tecnológicas e melhor desempenho.

Nessa perspectiva, fazem parte dos princípios da extensão rural uma série de atividades desenvolvidas no sentido de transformar sistemas produtivos no meio rural. Essas ações se fundamentam em políticas, especialmente na Política Nacional de Assistência Técnica e Extensão Rural (PNATER), criada em 2003 e implementada a partir de 2004. No ano de 2010, a PNATER se tornou lei e foi institucionalizada através da Lei 12.188/2010. Desde então, essa política vem sendo orientada pelo Programa Nacional de Assistência Técnica e Extensão Rural (PRONATER), e elaborada com base nos princípios da sustentabilidade, considerando a cultura e a capacidade coletiva dos agricultores familiares e a diversificação da agricultura familiar. O PRONATER é o mecanismo orientador da implantação da PNATER e define as diretrizes e metas para os serviços públicos de ATER no país, sendo elaborado anualmente para cada Plano Safra da Agricultura Familiar, com base nos Programas Estaduais de ATER e nas demandas do segmento da agricultura familiar.

$\mathrm{Na}$ agricultura familiar o papel desempenhado pelos serviços de ATER tem destaque, pois é fundamental para o processo de inclusão por meio do contínuo aperfeiçoamento dos sistemas de produção e dos mecanismos de acesso a recursos, considerando sempre a necessidade constante do aprendizado, da tecnologia e da infraestrutura de produção econômica. Os serviços de ATER têm a capacidade, ainda, de internalizar inovações (innovation production) e incentivar o surgimento de novidades (novelty production) e de formas de organização coletiva, a exemplo das cooperativas, associações e redes de comercialização. Assim, o modelo principal a ser adotado pelas ações de ATER precisa superar problemas resultantes dos modelos agrícolas convencionais, por décadas fomentados. Isto exige novas posturas que envolvam gestores, entidades prestadoras do serviço de assistência técnica e agricultores familiares, de forma participativa e inovadora.

Acredita-se que a ATER tem papel fundamental quanto a inovação no processo de desenvolvimento rural, no qual a agricultura familiar contribui como ambiente adequado, o que torna necessário os serviços de acompanhamento e de modernização de técnicas e práticas para resultar no campo mais produtivo, viável economicamente e atrativo socialmente. Diante disso, as questões que se colocam são: tendo em vista a agricultura familiar considerada precária, qual a realidade das ações de ATER no Território Rural Sertão Central Cabugi e Litoral Norte, no Rio Grande do Norte, especialmente na integração com a organização coletiva e o crédito? E qual a contribuição e quais dificuldades de se adotar a adequação sóciotécnica no âmbito da agricultura familiar? 
Como pressuposto, o fato do Território se constituir num ambiente frágil de desenvolvimento, as ações de ATER não se encontram em plena harmonia com o crédito rural e a organização coletiva, e a adequação sócio-técnica ainda se apresenta um desafio, precisando ser adaptada às necessidades do Território. Assim, o objetivo é analisar as ações de ATER, destacando a sua capacidade de integração com o crédito rural e a organização coletiva, e evidenciando a necessidade da adequação sócio-técnica no Território Sertão Central Cabugi e Litoral Norte.

\section{FUNDAMENTAÇÃO TEÓRICA:}

\subsection{ASSISTÊNCIA TÉCNICA E EXTENSÃO RURAL E A ADEQUAÇÃO SÓCIO- TÉCNICA}

Ao longo de muitos anos, e muito devido à modernização agrícola brasileira, as atividades relacionadas aos serviços de ATER apresentaram caráter difusionista em que, segundo Paiva (1971), tanto o processo de adoção de tecnologias (na esfera micro) pelo produtor, como a expansão dos pacotes tecnológicos (na esfera macro) pelas políticas governamentais, possuíam papel principal. Essa concepção difusionista vem desde início dos anos 1950, por influência de empresas privadas, a exemplo do grupo Rockfeller, com a criação da Associação de Crédito e Assistência Rural (ACAR), em Minas Gerais, no ano de 1949. A partir dos anos 1950 técnicos brasileiros foram enviados para os EUA, com a finalidade de fazer cursos em um processo de qualificação direcionada à concepção difusionista de ATER.

No entanto, conforme Nunes et al. (2020), a concepção de ATER em que o padrão técnico deveria ser baseado na transferência de tecnologias se afirmou com a Lei n. 6.126, de 6 de novembro de 1974, momento em que foi realizado o processo de estatização do Sistema Brasileiro de Extensão Rural com a criação da Empresa Brasileira de Assistência Técnica e Extensão Rural (EMBRATER). Neste contexto, em que a lógica de inovação passou a se alinhar aos preceitos das contribuições de Hayami e Ruttan (1985), os agricultores familiares eram induzidos à condição de depositários de tecnologias e de conhecimentos exógenos, sendo estes introduzidos muitas vezes "de cima" sem considerar as suas reais necessidades e de forma nem sempre adequada nas suas propriedades.

Com o processo de desestruturação das atividades, segundo Nunes et al. (2020), a redução da oferta e da qualidade dos serviços de ATER nos anos 1990 aconteceu devido à extinção da EMBRATER, surgindo discussões em torno de uma nova concepção de ATER pública, sobretudo após a criação do Programa Nacional de Fortalecimento da Agricultura Familiar (PRONAF), em 1996. De acordo com Caporal e Ramos (2006), através do Decreto № 4.739, de 13 de junho de 2003, o órgão responsável para coordenar as ações de ATER, o Departamento de Assistência Técnica e Extensão Rural (DATER), saiu do Ministério da Agricultura (MAPA) para o então Ministério do Desenvolvimento Agrário (MDA) e, no ano de 2003, a Política Nacional de Assistência Técnica e Extensão Rural (PNATER) foi criada, e efetivamente executada a partir do ano de 2004.

Conforme Nunes et al. (2020), a PNATER foi criada em 2003 e implementada a partir do ano de 2004, enquanto Política Nacional de ATER, se tornando lei no ano de 2010 e incorporada ao Programa Nacional de Assistência Técnica e Extensão Rural na Agricultura Familiar e na Reforma Agrária (PRONATER). Cabe ressaltar que a mesma Lei 12.188/2010 que instituiu a política foi a que, ao mesmo tempo, criou o programa. A proposta de ATER sugerida pela 
PNATER, conforme Caporal e Ramos (2006), é a que vem até os dias atuais e propõe um caráter menos difusionista e mais extensionista, trazendo consigo o apelo à sustentabilidade, além da diversificação da agricultura familiar em dinâmicas endógenas de desenvolvimento rural. Na PNATER são sugeridos métodos mais participativos com tecnologia e conhecimentos com ação mais intensiva e contínua, numa concepção que tende a ser contrária à de Hayami e Ruttan (1985).

Essa nova concepção de ATER sugerida pela PNATER está alinhada com a literatura internacional, em que contribuições como as de Ploeg e Wiskerke (2004), Ploeg (2008), Brunori et al. (2008), Knickel et al. (2009) e Moschitz et al. (2015) dão ênfase ao que passaram a definir inovação de "segunda ordem". Para acontecer essa "segunda ordem", são necessárias mudanças na internalização da inovação no sentido de realinhar a dinâmica da agricultura com as demandas reais da sociedade. Esta perspectiva reforça a necessidade de ações de ATER com característica mais extensionista, capazes de introduzir inovações (innovation production) e criar condições para que novidades (novelty production) possam surgir, especialmente no âmbito da agricultura familiar. $\mathrm{Na}$ verdade, essa perspectiva analisa aspectos institucionais das redes de aprendizagem e qualificação para uma agricultura familiar sustentável em dinâmicas regionais de desenvolvimento rural, sinalizando para atividades mais alinhadas com ponto de vista da adequação sócio-técnica.

Conforme Dagnino e Novaes (2005), a adesão à adequação sócio-técnica visa suprir a necessidade de parte essencial de uma prática em disseminação utilizada no sentido de apoiar iniciativas e empreendimentos a competirem com inovação alternativa e diversificada, mas em nível mais igualitário com os empreendimentos que utilizam inovações padronizadas, modernas e convencionais. Ou seja:

\begin{abstract}
A adequação sócio-técnica pode ser entendida como um processo que busca promover uma adequação do conhecimento científico e tecnológico (esteja ele já incorporado em equipamentos, insumos e formas de organização da produção, ou ainda sob a forma intangível e mesmo tácita), não apenas aos requisitos e finalidades de caráter técnicoeconômico, como até agora tem sido o usual, mas ao conjunto de aspectos de natureza socioeconômica e ambiental que constituem a relação Ciência, Tecnologia e Sociedade (DAGNINO; 2014).
\end{abstract}

De acordo com Katz e Cibotti (1976), a adequação sócio-técnica pode ser concebida por semelhança ao processo, associado a uma dinâmica de ajustes pelo aprendizado, a exemplo dos processos industriais dos anos 1960 ou dos pacotes tecnológicos que definiram modelos exógenos de modernização da agricultura a partir dos anos 1970, na qual a tecnologia dos países centrais foi introduzida e adaptada às condições de ambiente e técnico-econômicas brasileiras. No sentido de Katz e Cibotti (1976), a adequação sócio-técnica pode ser traduzida como uma dinâmica que possibilita ajustes do conhecimento tecnológico, acontecendo no processo produtivo e sem as limitações às definições hegemônicas de caráter econômico. Na verdade, pode ser estendida para além do econômico, considerando aspectos sociais, políticos e ambientais na relação ciência, tecnologia e sociedade.

Neste sentido, a possibilidade de adoção de um modelo de desenvolvimento alternativo impõe que o conhecimento "convencional" seja instrumento de uma adequação sócio-técnica para que, de uma forma mais participativa, o conhecimento alternativo seja capaz de se alinhar e atender aos seus valores e interesses. A adequação sócio-técnica é compreendida como a intervenção humana direta sobre o processo de criação da tecnologia, como 
também para uma nova configuração tecnológica visando interesses coletivos de um determinado segmento. É neste caminho que, na compreensão de Feenberg (2005), a adequação sócio-técnica se caracteriza e se define quando a tecnologia é submetida a valores e interesses diretamente relacionados à ação humana. Dessa forma, devido ao nível do controle humano, seja quando da sua elaboração ou no momento da necessidade da adequação a outros valores e interesses, estes últimos são diferentes dos originais.

Assim, de acordo com Novaes:

(...) como forma de viabilizar a possibilidade do processo transformador da adequação sócio-técnica, Feenberg propõe uma reconfiguração da técnica convencional incluindo "[...] variáveis como participação democrática no processo de trabalho, variáveis ambientais, critérios de saúde no trabalho, do impacto da técnica na saúde dos consumidores e desenvolvimento das potencialidades intelectuais dos trabalhadores" (NOVAES, 2007).

Já na compreensão de Coelho (2015), a adequação sócio-técnica combina as perspectivas da tecnociência com o humanamente controlável e como portadora de valores, pois a tecnociência é envolvida de valores capitalistas de caráter mais econômico que os reproduzem, que sinalizam para modelos insustentáveis e dificultam a transformação social. $\mathrm{Na}$ verdade, a questão não estaria no conhecimento em si, e sim na pequena capacidade de êxito das institucionalidades que agem como indutoras de modelos tecnológicos exógenos. No entanto, devido ao fato de não serem descartados totalmente, se busca sobre eles adotar um controle mais humano, mais coletivo e com maiores níveis de igualdade.

Trazendo para o ambiente da agricultura, especialmente dos agricultores familiares e suas organizações coletivas, os elementos utilizados para definir a adequação sociotécnica nesse contexto conduzem para a natureza de sua complexidade e diversificação. A dinâmica da produção agropecuária revela graus diferenciados de modernização, ou seja, em posições particulares da relação tempoespaço a produção agrícola torna-se artificial, enquanto em outras posições ela é baseada, principalmente, se não exclusivamente, no capital natural, o que é definido por Ploeg (2008) pelo conceito de co-produção ${ }^{4}$. Outro elemento importante é a base de recursos $^{5}$, que pode ser construída de forma extensiva ou limitada, sendo a tecnologia ajustada e controlada por atores diretamente envolvidos, numa adequação socio-técnica, ou levar estes atores à submissão e ao controle externo. Para Ploeg (2008), a base de recursos é a infraestrutura de produção econômica que proporciona o espaço de manobra do agricultor familiar, e ela não se separa de elementos opostos, a exemplo do capital e do trabalho, ou do trabalho mental e manual. Nesta, os recursos tecnológicos representam uma unidade orgânica e são controlados pelos atores diretamente envolvidos, e a regulação é derivada do

\footnotetext{
4 De acordo com Ploeg (2008), co-produção seria a melhoria contínua da técnica e das práticas através do investimento no trabalho familiar (a exemplo da construção de sistemas de irrigação), e o tempo gasto muitas vezes no melhoramento dos recursos (criando animais mais produtivos através de seleção, ou obtendo melhores variedades de plantas), ambos a base de recursos e o processo de produção tendem a ser cada vez mais melhorados. Dessa forma, mais rendimentos resultarão em maiores ganhos, os quais, por sua vez, irão compensar a quantidade de trabalho acrescentado.

${ }^{5} \mathrm{~A}$ base de recursos é, ao longo do tempo, formada e aperfeiçoada pelos agricultores familiares e define os graus de mercantilização e os diferentes estilos de agricultura dos núcleos a partir do padrão tecnológico adotado, seja este constituído por tecnologias modernas e obtidas externamente, produzidas no interior da propriedade ou através da combinação das duas situações.
} 
repertório cultural da localidade. Nesse ambiente é destacada a centralidade no trabalho familiar, onde sua intensidade deverá considerar a quantidade e a qualidade. E nesse contexto fazem-se necessários os serviços de ATER, pois os movimentos de aproximação ou distanciamento com mercados variam na mesma proporção (PLOEG, 2008).

Tentando caracterizar a condição da agricultura familiar, para efeito deste estudo, Ploeg (2008) coloca que o agricultor familiar está apto a produzir níveis crescentes de valor adicionado, ou de valor agregado. E é o foco no valor adicionado o que distingue o modo familiar de produção de outros modos, pois nesse, segundo Ploeg (2008), a constituição da base do recurso se aproxima da adequação sócio-técnica. Neste contexto, os recursos materiais, tecnológicos e sociais disponíveis representam uma unidade orgânica e são ajustados e controlados pelos atores diretamente envolvidos no processo de trabalho. E quanto às institucionalidades, as relações entre os atores ocorrem no âmbito regional, e são derivadas dos mecanismos locais de regulação e do repertório cultural (PLOEG, 2008).

A defesa de Ploeg (2008) é a de que a essa centralidade no trabalho familiar deverá associar três elementos essenciais: 1) a natureza das tecnologias aplicadas, as quais deverão ser alternativas e orientadas no sentido contrário às convencionais; 2) uma importância especial à intensificação e investimento no trabalho familiar, este visando níveis crescentes de qualidade; e 3) a produção de novidades (novelty) tecnológicas que surgem com as necessidades de ajuste no processo de produção, onde se torna fundamental o acompanhamento técnico (ATER). Considerando a tecnologia na associação entre os três pontos citados por Ploeg (2008) no processo de mudança, ela se apresenta como um elemento importante que afeta o funcionamento da economia local e regional, seja a tecnologia alternativa ou convencional, sendo responsável pela alteração nas estruturas tanto no âmbito interno da unidade de produção como nas relações com o ambiente externo.

Esse processo dá forma a um ciclo no qual a qualidade do trabalho familiar é aprimorada pelo aprendizado tecnológico, se constituindo em um ambiente em que se faz necessário a presença constante e contínua dos serviços de acompanhamento técnico (ATER) aos agricultores familiares e suas organizações coletivas. No Brasil, este tipo de serviço se caracterizou historicamente pelo apoio preferencial dado àquelas dinâmicas rurais mais integradas da modernização baseada em tecnologias convencionais, especialmente assumindo o papel de difusão da crença na noção de progresso.

Os recursos utilizados destacados na análise foram basicamente a terra, os recursos financeiros (crédito), o trabalho familiar (em cooperativas) e a tecnologia associada ao acompanhamento técnico (ATER). Assim, a partir das estratégias, sejam pelo caminho da organização coletiva ou das empresas globalizadas, da intensificação do trabalho familiar, no sentido da estratégia labour-driven intensification definida por Ploeg (2008), ou por maior contratação de força de trabalho, do uso intenso de tecnologias convencionais ou alternativas, acredita-se que cada dinâmica agrícola apresenta resultados diferenciados. Do ponto de vista técnico, esse rendimento aumenta com o uso crescente de insumos e fatores de produção por objeto de trabalho, ou eficiência técnica melhorada, partindo de práticas e ações no nível micro baseadas na organização coletiva, na agregação de valor e no acesso a mercados. O foco dessa estratégia se concentra na criação de oportunidades para cada vez mais pessoas possam permanecer no campo, o que, para Ploeg e Wiskerke (2004), serviços de ATER são necessários na agricultura familiar por esta se apresentar como ambiente fértil para o surgimento de novidades 
(novelty production) e de inovações (innovation production), e, consequentemente, para a adequação socio-técnica.

Esse é um approach que se apresenta adequado para a dinamização econômica nos Territórios, especialmente via ações de ATER fundamentadas na concepção menos difusionista e mais extensionista da PNATER, ou na perspectiva de inovação de "segunda ordem". Para Nunes et al. (2018), essa constatação se justifica quando da melhor utilização da estrutura econômica e de organização coletiva dos agricultores familiares (sua base de recursos), com a capacidade de fazer surgir tecnologias e técnicas novas de produção, as quais possibilitam o que Ploeg e Wiskerke (2004) definem seeds of transition (sementes da transição). Para Ploeg e Wiskerke (2004), as novidades e as inovações possuem trajetórias diferentes, pois enquanto as inovações seriam exógenas, convencionais e definidas como padrão, as novidades seriam endógenas, alternativas e diversificadas e se caracterizariam pela contextualização, internalização e territorialização.

A contextualização diz respeito às condições como os agricultores adquirem o conhecimento para ajustar tecnologias e gerar as novidades no âmbito econômico, social e institucional da agricultura familiar. Geralmente, conforme Stuiver e Wiskerke (2004), as novidades e as inovações são o resultado da "fusão de crenças e concepções" entre o mundo dos agricultores em que, de acordo com Oliveira et al. (2011) "predomina o contato com a natureza e o uso do conhecimento natural, com mundos de cientistas, ambientalistas, consumidores, extensionistas, etc., em que predomina mais o conhecimento científico". A internalização refere-se à dinâmica endógena a partir da base de recursos que sustenta a produção das novidades (e a adequação socio-técnica), e onde predomina o uso de recursos internos, dinâmica que acontece numa região ou unidade produtiva familiar. De acordo com Oliveira et al. (2011), isso faz com que as novidades sejam alternativas mais eficientes, pois, com rearranjos no uso dos recursos, os agricultores conseguem aumentar a produção e baixar os custos da atividade agrícola. E, por último, conforme Stuiver e Wiskerke (2004), a territorialização envolve a ideia de que as novidades nascem de dentro em um local, ou território, e para Oliveira et al. (2011), o surgimento depende do tempo, do aprendizado e da cultura em que o trabalho agrícola está inserido.

Neste sentido, Nunes et al. (2018) chamam a atenção para formas de ação do desenvolvimento que no âmbito territorial têm permitido um avanço significativo visando deslocar a perspectiva da adequação socio-técnica como alternativa nas soluções tecnológicas na agricultura familiar dos Territórios. Entretanto, ainda há uma insistência na introdução e adoção de tecnologias convencionais da modernização agrícola, refletindo a necessidade de mudança, a exemplo da inovação de "segunda ordem", na concepção de ATER nos Territórios rurais.

Com base nessa perspectiva, o Território Sertão Central Cabugi e Litoral Norte, no Rio Grande do Norte, é pouco desenvolvido, talvez por reproduzir receitas antigas em modelos que se baseiam em concepções tecnológicas convencionais. Para Silva et al. (2017) e Nunes et al. (2019), a sua constituição teve o enfoque territorial como identidade numa estratégia essencialmente integradora de espaços, de atores, mercados e políticas de intervenção. As bases fundamentais para a sua formação tiveram como pilares o discurso da equidade, do respeito à diversidade, da solidariedade, da justiça social, do sentimento de pertencimento, da valorização da cultura e da inclusão produtiva e da gestão social (NUNES et al., 2019).

Como enfatiza Nunes et al. (2015a), a concepção de desenvolvimento territorial no Brasil é relativamente recente e tem influenciado o Estado na organização dos atores no sentido de engendrar dinâmicas locais e regionais por meio de políticas de desenvolvimento. As políticas públicas são fundamentais quando da contribuição para integrar o tripé acesso ao crédito, organização coletiva 
e acompanhamento técnico, além de possibilitar a adequação socio-técnica no processo de dinamização e desenvolvimento dos Territórios. Assim, a partir da percepção de que o rural não pode ser visto apenas como um espaço de produção agrícola, uma nova concepção de ATER deve considerar aspectos econômicos, culturais, sociais e ambientais, apesar das dificuldades nos processos da adequação sócio-técnica.

\section{METODOLOGIA}

O Rio Grande do Norte é composto por dez Territórios, no entanto, este trabalho concentra-se no Território Rural Sertão Central Cabugi e Litoral Norte, que foi criado no ano de 2008, mas reconhecido como Território apenas no ano de 2013. Este Território rural abrange uma área de $5.215,156 \mathrm{Km}^{2}$ e é formado por 10 municípios: Afonso Bezerra, Angicos, Caiçara do Rio do Vento, Fernando Pedroza, Galinhos, Guamaré, Lajes, Macau, Pedra Preta e Pedro Avelino, conforme figura 1.

Figura 1 - Recorte do Território Rural Sertão Central Cabugi e Litoral Norte, Rio Grande do Norte.

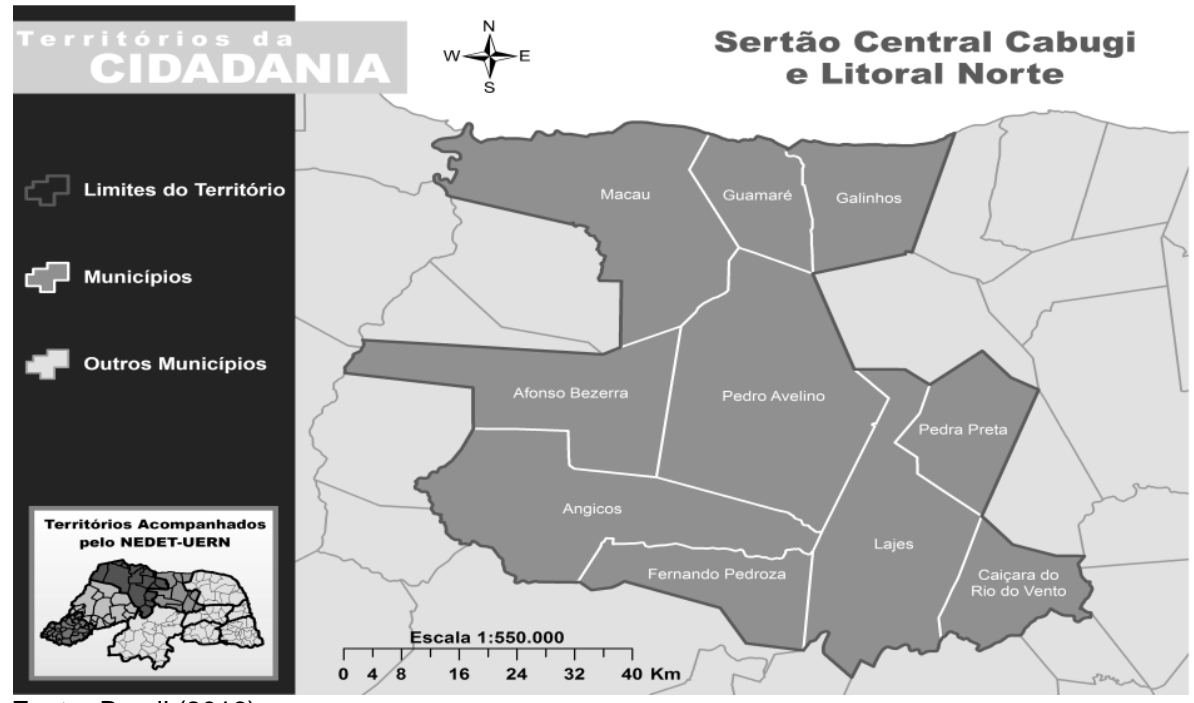

Fonte: Brasil (2016).

Para buscar aferir a qualidade dos serviços de ATER no Território, foi realizado um levantamento a partir de roteiro norteador enviado pela Secretaria de Desenvolvimento Territorial (SDT), do então Ministério do Desenvolvimento Agrário (MDA). Os entrevistados foram técnicos de ATER (EMATER e Organizações da Sociedade Civil), representantes de associações dos dez municípios, dois agentes de desenvolvimento cedidos pelas dez prefeituras municipais, e três representantes de entidades privadas que também atuam no Território com serviços de ATER. A percepção dos envolvidos pode ser considerada de significativa relevância para o levantamento das demandas por soluções tecnológicas, considerando as informações qualitativas como base para estratégias de ação, o que possibilitou aos agricultores a problematização de sua realidade e a comparação entre os municípios do Território Rural Sertão Central Cabugi e Litoral Norte. 
A metodologia foi a do "Diagrama de Venn" (KUMMER, 2007), conforme a figura 2, utilizada durante as visitas nos dez municípios que compõem o Território Sertão Central Cabugi e litoral Norte, o que permitiu representar a interconexão de várias instituições ou pessoas-chave dentro de uma comunidade ou organização, que a partir dos elos criados são importantes na tomada de decisão. Foram repassadas ao grupo informações preliminares da sistematização para leitura, discussão e tirada de conclusões, e os agricultores familiares, os sindicatos, as igrejas selecionaram as organizações com toda autonomia e flexibilidade com as quais mantêm contatos e ou que influenciam no desenvolvimento e perspectiva dos residentes do meio rural.

Figura 2 -Diagrama de Venn do Território Rural do Sertão Central Cabugi e litoral Norte.

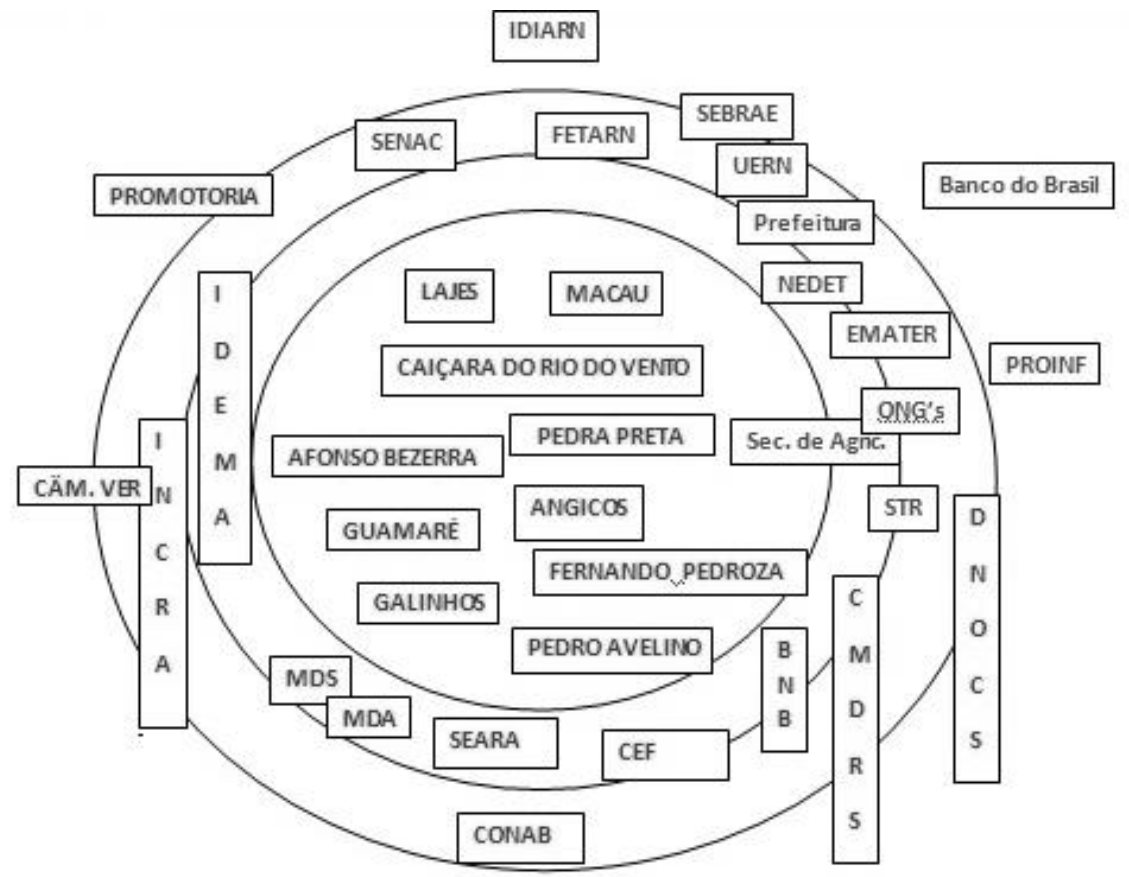

Fonte: Levantamento pesquisa de campo (2017). Elaboração dos autores.

No centro do diagrama colocaram-se todos os dez municípios e em sua volta as instituições, as quais tiveram seus nomes escritos em tarjetas. A distância do centro e as tarjetas demonstram o grau e a importância da relação, ou seja, quanto mais próximos maior o contato entre si e a influência no desenvolvimento do processo entre o público beneficiário e as entidades pertencentes às esferas de poder federal, estadual e municipal. Assim, as targetas com maior proximidade representam instituições ou instâncias que se apoiam mais diretamente, e as targetas com maior distância são as que que fornecem pouco apoio aos agricultores.

Foram realizados 22 encontros no período de 26 de agosto a 19 de setembro de 2016, todos relatados de forma escrita com a participação de pesquisadores, técnicos e agricultores familiares para levantar informações, qualificá-las através da reflexão coletiva, e quantificá-las, utilizando técnicas 
participativas e propiciando a construção do conhecimento sobre a contribuição de cada ente público. E, paralelo a estas atividades, foi realizada uma ampla revisão bibliográfica com 0 intuito de interpretar e explicar 0 ambiente empírico, acompanhada pela busca e organização de dados de fontes secundárias, estes analisados e apresentados nos resultados.

Procurou-se compreender quais entidades se propunham a possibilitar ou fomentar a inserção e uma maior qualidade das políticas públicas para o atendimento das demandas por soluções tecnológicas. As entidades foram se adaptando ao longo da sistematização, e o que orientou modificações das tarjetas até o seu formato final foi a influência maior ou menor do público participante por entidade. Especificamente, foi possível visualizar a importância da entidade dentro de uma abordagem sistêmica e compreender as lacunas existentes, pois estas lacunas estariam dificultando alternativas tecnológicas e seus ajustes, além de não integrarem políticas fundamentais para a dinamização e desenvolvimento do Território Rural Sertão Central Cabugi e Litoral Norte.

\section{RESULTADOS E DISCUSSÃO}

\subsection{O TERRITÓRIO RURAL SERTÃO CENTRAL CABUGI E LITORAL NORTE E AS FORMAS RECENTES DE ASSISTÊNCIA TÉCNICA E EXTENSÃO RURAL (ATER)}

Segundo dados do IBGE (2017), o Território Rural Sertão Central Cabugi e Litoral Norte possui uma população de 92.242 habitantes nos dez municípios que o constituem, dos quais 30.626 residem na área rural, correspondendo a $33,2 \%$ do total. Quanto às suas características socioeconômicas, um dos pontos que chama a atenção é a disparidade entre os municípios com relação ao Produto Interno Bruto (PIB) e o PIB per capita. Dos dez municípios que constituem o Território, três se destacam: Guamaré, Macau e Galinhos. O PIB de Guamaré alcança os R\$1,37 bilhões para uma população de pouco mais de 12 mil habitantes, chegando à impressionante renda per capita de $\mathrm{R} \$ 110.063,42^{6}$, uma das maiores do país. Macau e Galinhos apresentam PIB per capita de $R \$ 30.072,61$ e $R \$ 22.998,94$, respectivamente, como mostra a tabela 1. Os demais municípios possuem renda per capita aproximadas.

\footnotetext{
6 Essa disparidade no PIB dos municípios é devido ao repasse dos royalties sobre a produção de petróleo e gás, no qual Guamaré, Macau e Galinhos se destacam com PIBs per capita mais elevados.
} 
Tabela 1 - Características socioeconômicas do Território Rural Sertão Central Cabugi, Litoral Norte, 2017.

\begin{tabular}{l|r|r|r|r|r|c}
\hline \hline \multirow{2}{*}{ Município } & \multirow{2}{*}{$\begin{array}{c}\text { PIB (em } \\
\text { R } \mathbf{2} \text { mil) }\end{array}$} & \multirow{2}{*}{$\begin{array}{c}\text { PIB per } \\
\text { capita (R\$) }\end{array}$} & \multicolumn{5}{|c}{ População } \\
\cline { 5 - 8 } & & & Rural & \multicolumn{1}{c}{$\%$} & Urbana & Total \\
\hline \hline Afonso Bezerra & 64684 & 5780,03 & 5.085 & $47.1 \%$ & 5.759 & 10.844 \\
\hline Angicos & 90945 & 7639,24 & 1.464 & $12,7 \%$ & 10.085 & 11.549 \\
\hline $\begin{array}{l}\text { Caiçara do Rio } \\
\text { do Vento }\end{array}$ & 25570 & 7241,46 & 782 & $23,7 \%$ & 2.526 & 3.308 \\
\hline $\begin{array}{l}\text { Fernando } \\
\text { Pedroza }\end{array}$ & 21339 & 7113,03 & 417 & $14,7 \%$ & 2.437 & 2.854 \\
\hline Galinhos & 56255 & 22998,94 & 921 & $42,3 \%$ & 1.238 & 2.159 \\
\hline Guamaré & 1365226 & 110063,42 & 7.997 & $64,6 \%$ & 4.407 & 12.404 \\
\hline Lajes & 74800 & 6814,22 & 2.313 & $22,2 \%$ & 8.068 & 10.381 \\
\hline Macau & 924703 & 30072,61 & 6.988 & $24,1 \%$ & 21.966 & 28.954 \\
\hline Pedra Preta & 19234 & 7377,66 & 1.600 & $61,7 \%$ & 990 & 2.590 \\
\hline Pedro Avelino & 42443 & 5906,31 & 3.051 & $42,5 \%$ & 4.120 & 7.171 \\
\hline \hline
\end{tabular}

Fonte: IBGE (2017). Elaboração dos autores.

O aspecto econômico destacado nas disparidades entre os municípios do Território Rural Sertão Central Cabugi e Litoral Norte esconde uma face desigual e de subdesenvolvimento, apesar do Território possuir uma diversidade econômica baseada em recursos naturais capaz de possibilitar muitas oportunidades. No meio rural são encontradas atividades agrícolas e uma agroindústria artesanal que processa frutas, carnes e laticínios, além de uma agricultura familiar ainda precária que tem buscado se afirmar e se estruturar. Nos municípios litorâneos destaca-se a atividade industrial ligada à exploração de sal marinho, petróleo e gás natural, ceramista e mineral, com intensa ampliação de parques de energia eólica.

No entanto, apesar da abundância em recursos naturais, da existência de atividades econômicas importantes, da presença marcante de estabelecimentos da agricultura familiar e de cooperativas, a fragilidade socioeconômica do Território é revelada nos seus indicadores de desenvolvimento humano, especialmente o Índice de Desenvolvimento Humano Municipal (IDH-M) das Nações Unidas. Como mostra a tabela 2, os municípios do Território Rural Sertão Central Cabugi e Litoral Norte possuem estabelecimentos rurais familiares, poucas cooperativas e apresentam IDH-M abaixo de 0,5, um baixo desenvolvimento considerando a escala entre 0 e 1. 
Tabela 2 - Índice de Desenvolvimento Humano Municipal (IDH-M), estabelecimentos rurais e organizações cooperativas dos municípios do Território Sertão Central

Cabugi e Litoral Norte.

\begin{tabular}{|c|c|c|c|c|c|c|c|}
\hline \multirow{2}{*}{ Município } & \multicolumn{3}{|c|}{ IDHM } & \multicolumn{3}{|c|}{$\begin{array}{l}\text { Estabelecimentos } \\
\text { agropecuários }\end{array}$} & \multirow{2}{*}{$\begin{array}{l}\text { Cooperativas } \\
\text { da agricultura } \\
\text { familiar }\end{array}$} \\
\hline & 1991 & 2000 & 2010 & $\begin{array}{c}\text { Agricultura } \\
\text { Familiar } \\
\end{array}$ & $\begin{array}{c}\text { Não } \\
\text { Familiar } \\
\end{array}$ & Total & \\
\hline $\begin{array}{l}\text { Afonso } \\
\text { Bezerra }\end{array}$ & 0,343 & 0,456 & 0,585 & 754 & 42 & 796 & 01 \\
\hline Angicos & 0,401 & 0,528 & 0,624 & 125 & 54 & 179 & 01 \\
\hline $\begin{array}{l}\text { Caiçara } \\
\text { do Rio do } \\
\text { Vento } \\
\end{array}$ & 0,274 & 0,428 & 0,587 & 220 & 88 & 308 & - \\
\hline $\begin{array}{l}\text { Fernando } \\
\text { Pedroza }\end{array}$ & 0,310 & 0,476 & 0,597 & 25 & 28 & 53 & - \\
\hline Galinhos & 0,303 & 0,417 & 0,564 & 3 & 16 & 19 & - \\
\hline Guamaré & 0,344 & 0,444 & 0,626 & 148 & 25 & 173 & - \\
\hline Lajes & 0,351 & 0,486 & 0,624 & 303 & 68 & 371 & 02 \\
\hline Macau & 0,405 & 0,556 & 0,665 & 68 & 25 & 93 & 01 \\
\hline $\begin{array}{l}\text { Pedra } \\
\text { Preta }\end{array}$ & 0,279 & 0,388 & 0,558 & 261 & 29 & 290 & 01 \\
\hline $\begin{array}{l}\text { Pedro } \\
\text { Avelino }\end{array}$ & 0,289 & 0,469 & 0,583 & 509 & 116 & 625 & 01 \\
\hline
\end{tabular}

Fonte: IBGE (2017) e SESCOOP-RN (2018). Elaboração dos autores.

Quanto às atividades agropecuárias do Território, as consideradas de maior relevância são a ovinocaprinocultura e a bovinocultura leiteira, seguida da piscicultura e da produção de mel em pequena escala, além da pesca artesanal nos municípios litorâneos, sendo a sardinha o principal produto. A criação de ovinos e caprinos é a maior vocação, pois esses animais se adaptaram e se desenvolveram com facilidade às condições edafoclimáticas do semiárido.

A pesquisa mostrou que o leite é o produto mais processado, seguido da carne, sendo estes dois produtos destinados para mercados locais e regionais. A Associação dos Criadores de Ovinos e Caprinos do Sertão do Cabugi (ACOSC), sediada no município de Lages, e a Associação de Produtores Agropecuaristas do Sertão de Angicos (APASA), sediada no município de Angicos, são vinculadas às cooperativas e principais organizadoras dos produtores da região. A APASA é uma importante agroindústria para a cadeia produtiva de animais, por possuir uma estrutura de processamento do leite com capacidade de 20.000 litros de leite/dia.

A cadeia produtiva dos animais, que tem o leite e a carne como os principais produtos, é também a que faz funcionar o maior número de estabelecimentos com agroindústria rural no Território. Como mostra a tabela 3 , a manteiga, o queijo e o requeijão, carne de bovinos, de suínos e carnes de outros animais (estas sendo de caprinos e ovinos, aves etc.) são os produtos predominantes nas agroindústrias do Território. Esses produtos afirmam a característica do meio rural do Território e um elo com as ações de ATER. E as agroindústrias, apesar de iniciativas de dinamização das mais promissoras, ainda são estruturas artesanais e frágeis, pois surgiram nos últimos quinze anos como sementes de uma possível transição. 
Tabela 3 - Número de estabelecimentos agropecuários com agroindústria familiar rural (em unidades).

\begin{tabular}{l|c|c|c|c|c|c|c|c|c|c}
\hline \hline Municípios & Total & $\begin{array}{l}\text { Do- } \\
\text { ces/ } \\
\text { ge- } \\
\text { léias }\end{array}$ & $\begin{array}{l}\text { Fari- } \\
\text { nha } \\
\text { man- } \\
\text { dioca }\end{array}$ & $\begin{array}{l}\text { Fu- } \\
\text { bá } \\
\text { mi- } \\
\text { Iho }\end{array}$ & $\begin{array}{l}\text { Man- } \\
\text { teiga }\end{array}$ & $\begin{array}{l}\text { Queijo/ } \\
\text { requei- } \\
\text { jão }\end{array}$ & $\begin{array}{l}\text { Car- } \\
\text { ne } \\
\text { bovi- } \\
\text { nos }\end{array}$ & $\begin{array}{l}\text { Carne } \\
\text { suínos }\end{array}$ & $\begin{array}{l}\text { Carne } \\
\text { outros } \\
\text { animais }\end{array}$ & $\begin{array}{l}\text { Car- } \\
\text { vão } \\
\text { vege- } \\
\text { tal }\end{array}$ \\
\hline \hline $\begin{array}{l}\text { Rio G. do } \\
\text { Norte }\end{array}$ & $\mathbf{4 1 6 4}$ & $\mathbf{2 0 8}$ & $\mathbf{6 0 0}$ & $\mathbf{5}$ & $\mathbf{1 7 2}$ & $\mathbf{1 3 6 3}$ & $\mathbf{5 9}$ & $\mathbf{1 8 8}$ & $\mathbf{4 8 5}$ & $\mathbf{3 2 0}$ \\
\hline $\begin{array}{l}\text { Afonso } \\
\text { Bezerra }\end{array}$ & $\mathbf{4 2}$ & 3 & - & 1 & 1 & 5 & - & 2 & 25 & 2 \\
\hline $\begin{array}{l}\text { Angicos } \\
\text { Caiçara do }\end{array}$ & $\mathbf{8}$ & 1 & - & - & - & 5 & - & - & 1 & - \\
$\begin{array}{l}\text { Rio do } \\
\text { Vento }\end{array}$ & $\mathbf{5 0}$ & 1 & - & - & - & 4 & - & 5 & 28 & 12 \\
\hline $\begin{array}{l}\text { Fernando } \\
\text { Pedroza }\end{array}$ & $\mathbf{1 9}$ & 1 & - & - & - & 8 & - & - & - & 10 \\
\hline Galinhos & $\mathbf{1}$ & - & - & - & - & 1 & - & - & - & - \\
\hline Guamaré & $\mathbf{0}$ & - & - & - & - & - & - & - & - & - \\
\hline $\begin{array}{l}\text { Lajes } \\
\text { Macau }\end{array}$ & $\mathbf{1 1 7}$ & - & - & - & - & 13 & 1 & 5 & 42 & 56 \\
\hline Pedra Preta & $\mathbf{4 3}$ & 5 & 13 & - & - & 12 & - & 3 & - & 10 \\
\hline $\begin{array}{l}\text { Pedro } \\
\text { Avelino }\end{array}$ & $\mathbf{1 4 1}$ & - & - & - & - & 8 & 1 & 5 & 97 & 30 \\
\hline $\begin{array}{l}\text { TOTAL } \\
\text { Território }\end{array}$ & $\mathbf{4 2 4}$ & $\mathbf{1 1}$ & $\mathbf{1 3}$ & $\mathbf{1}$ & $\mathbf{2}$ & $\mathbf{5 8}$ & $\mathbf{2}$ & $\mathbf{2 0}$ & $\mathbf{1 9 3}$ & $\mathbf{1 2 0}$ \\
\hline \hline
\end{tabular}

Fonte: IBGE (2017). Elaboração dos autores.

Como constatado na pesquisa, o maior entrave para ampliar as agroindústrias do Território é a pouca estrutura e a reduzida diversificação de cadeias produtivas, e, em especial a de animais, na qual a média de produção alcança apenas 14 litros/dia em tempos de seca. Outra limitação vem dos agricultores, que não acreditam que a ovinocaprinocultura, por ser entregue a empresários e não à cooperativa, possa se tornar a principal cadeia de dinamização econômica do Território e ambiente para novidades e a internalização de inovações.

Considerando a importância da interação entre o crédito, organização coletiva e acompanhamento técnico para que as políticas de ATER obtenham cada vez mais um melhor desempenho, se faz necessária a existência de uma infraestrutura produtiva e de organização coletiva por parte da agricultura familiar, que é mais comumente construída por meio de financiamentos. Quando a agricultura familiar já possui boa infraestrutura produtiva e de organização coletiva, a obtenção de crédito tende mais para a modalidade custeio, pois este é um recurso financeiro de curto prazo que age como insumo e é utilizado na estrutura para gerar riqueza nova. Quando a infraestrutura existente é precária e deficiente, a tendência é obter cada vez menos recursos de custeio e mais da modalidade investimento, que é um recurso de longo prazo utilizado para construir a estrutura. $E$ foi justamente essa segunda constatação que prevaleceu com os valores de crédito obtidos, informados no gráfico 1, do Programa Nacional de Fortalecimento da Agricultura Familiar (PRONAF) no Território, de 2011 a 2018. 
Gráfico 1 - Território Rural Sertão Central Cabugi e Litoral Norte: valores do

PRONAF custeio e investimento (em R \$) de 2011 a 2018.

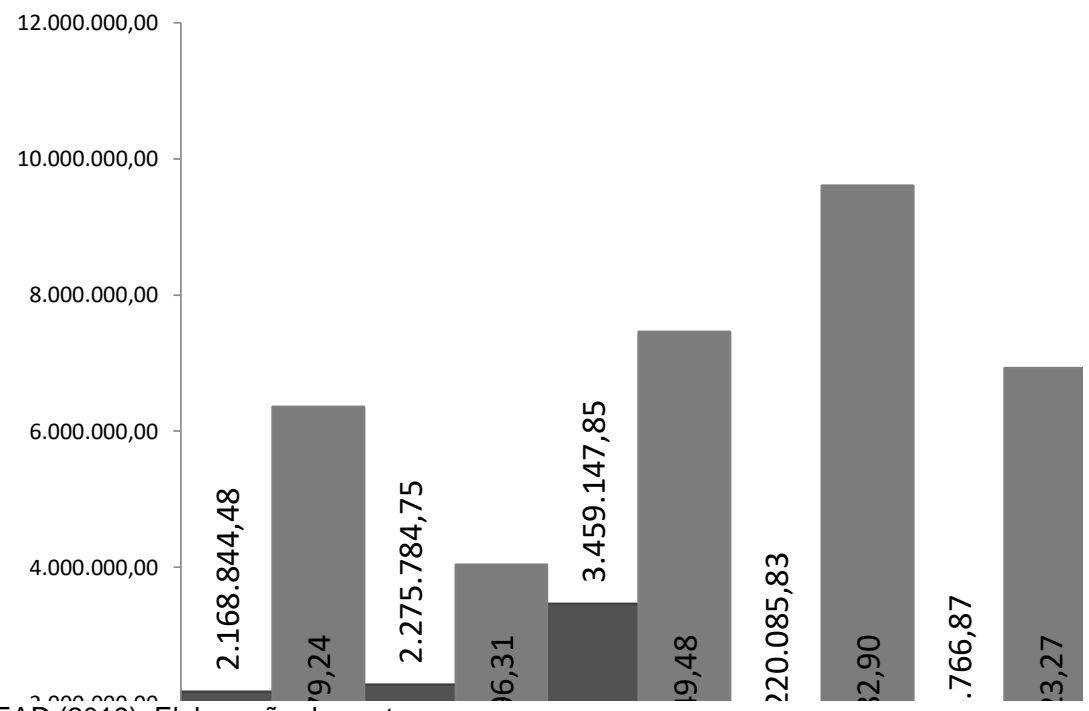

Fonte: SEAD (2019). Elaboração dos autores.

Essa é uma das características de regiões pouco desenvolvidas com atividades agrícolas precárias e de baixo desempenho, onde a insuficiência e a deficiência da estrutura de produção e de organização coletiva reduzem a obtenção do crédito custeio, impossibilitando a geração de riqueza nova e, consequentemente, limitando a dinamização das atividades e as ações de ATER. Da mesma forma, entre as modalidades de microcrédito no Território que operacionalizam o PRONAF B, segundo Nunes et al. (2015b), a maior parte do AGROAMIGO foi aplicada em investimento pecuário, conforme tabela 4.

Tabela 4 - Dez anos do AGROAMIGO Investimento e custeio no Sertão Central Cabugi e Litoral Norte de 2005 a 2015.

\begin{tabular}{l|c|c|c|r|r|r|r|r|r|r|r}
\hline \multicolumn{10}{c}{ TERRITÓRIO SERTÃO CENTRAL CABUGI E LITORAL NORTE } \\
\hline & $\mathbf{2 0 0 5}$ & $\mathbf{2 0 0 6}$ & $\mathbf{2 0 0 7}$ & $\mathbf{2 0 0 8}$ & $\mathbf{2 0 0 9}$ & $\mathbf{2 0 1 0}$ & $\mathbf{2 0 1 1}$ & $\mathbf{2 0 1 2}$ & $\mathbf{2 0 1 3}$ & $\mathbf{2 0 1 4}$ & $\mathbf{2 0 1 5}$ \\
\hline $\begin{array}{l}\text { Custeio } \\
\text { agrícola }\end{array}$ & 0,00 & 0,00 & 0,00 & 0,00 & 0,00 & 0,00 & 0,00 & 0,00 & 0,00 & 0,00 & 0,00 \\
\hline $\begin{array}{l}\text { Custeio } \\
\text { pecuário }\end{array}$ & 0,00 & 0,00 & 0,00 & 0,00 & 0,00 & 0,00 & 0,00 & 0,33 & 17,4 & 1,88 & 1,25 \\
\hline $\begin{array}{l}\text { Investi- } \\
\text { mento } \\
\text { agrícola }\end{array}$ & 0,00 & 5,53 & 7,54 & 5,91 & 1,91 & 0,47 & 0,74 & 0,07 & 8,38 & 2,82 & 0,00 \\
$\begin{array}{l}\text { Investi- } \\
\text { timento } \\
\text { pecuário }\end{array}$ & 100,0 & 94,4 & 92,4 & 94,0 & 98,0 & 99,5 & 99,2 & 99,6 & 74,1 & 95,3 & 98,7 \\
\hline
\end{tabular}

Fonte: Nunes et al. (2015b).

As modalidades investimento e custeio agrícola e pecuário do AGROAMIGO mostram, ainda, uma pequena capacidade do Território de gerar diversificação das atividades rurais, limitando-se tanto na produção como nas 
iniciativas de agroindústria artesanal na cadeia produtiva de animais. A concentração em apenas uma cadeia produtiva de caráter tradicional, com pouca capacidade para gerar agregação de valor, tem limitado formas recentes de ATER e não tem sido uma boa estratégia. Ou seja, a concentração na cadeia produtiva de animais tem se mostrado insuficiente para desencadear processos e internalizar inovações (innovation production), fazer surgir novidades (novelty production) e possibilitar oportunidades, a exemplo da estratégia labour driven-intensification.

Quando analisada a distribuição dos valores do PRONAF por município, a pesquisa revelou que Afonso Bezerra e Pedro Avelino foram os que mais obtiveram recursos do crédito da modalidade investimento (e menos custeio) no período de 2011 a 2018, conforme se observa no gráfico 2. Esses dois municípios são os que possuem os maiores números de estabelecimentos familiares do Território, com significativa presença de projetos de reforma agrária, onde Afonso Bezerra possui 754 estabelecimentos e Pedro Avelino possui 509 estabelecimentos. Em seguida, se destacam na obtenção dos recursos do crédito da modalidade investimento (e ainda menos custeio) os municípios de Lages, Angicos, Guamaré e Pedra Preta.

Gráfico 2 - Território Rural Sertão Central Cabugi e Litoral Norte: PRONAF custeio e investimento/município (em $\mathrm{R} \$$ ) no perído de 2011 a 2018.

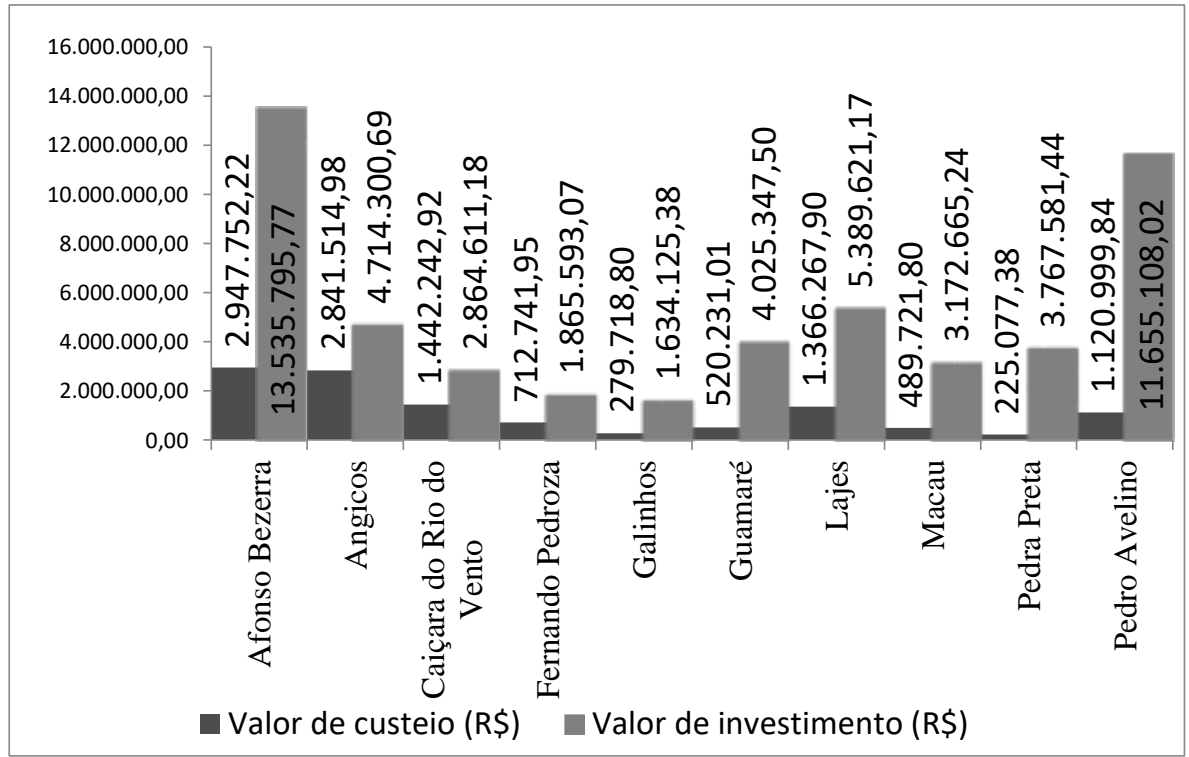

Fonte: SEAD (2019). Elaboração dos autores.

Cabe ressaltar que, na maioria das vezes, as políticas são descontínuas e não levam em conta as especificidades por desconsiderar a diversidade e a heterogeneidade dos Territórios. E o caráter bem-sucedido do desenvolvimento territorial tende a surgir por meio do engendramento de projetos econômicos relacionados com serviços contínuos e de qualidade de ATER, que sinalizem para um padrão alternativo baseado na ação coletiva e na sustentabilidade. A noção de sustentabilidade que tem acompanhado as ações no Território implica em formas recentes de ATER, com tecnologias alternativas (novelty production) à inovação padrão (innovation production). 
No entanto, quando analisados os registros de atendimentos de ATER e de famílias atendidas no Território no período de 2011 a 2018, os dados da pesquisa mostram uma ação descontínua das ações de ATER, apresentando um vazio de 2011 a 2013 e a presença mais significativa de 2014 até 2016, conforme se observa na tabela 5. Os registros de atendimentos de ATER e de famílias atendidas de 2014 a 2016 são das ações executadas pela Universidade através do Núcleo de Extensão em Desenvolvimento Territorial (NEDET), com a orientação da SDT/MDA. No momento em que a relação entre a Universidade e a SDT/MDA foi finalizada, as ações de ATER também foram deixando de existir, revelando a fragilidade dessa política devido à descontinuidade e à vulnerabilidade de uma agricultura familiar precária em que os agricultores passam a reproduzir o círculo vicioso de limitações na busca por soluções tecnológicas e adequação sócio-técnica.

Tabela 5 - № de atendimentos e de famílias atendidas com ATER de 2011 a 2018, no Território Rural Sertão Central Cabugi e Litoral Norte.

\begin{tabular}{|c|c|c|c|c|c|c|c|c|c|}
\hline Municípios & $\begin{array}{c}\text { Assistência } \\
\text { Técnica e Extensão } \\
\text { Rural }\end{array}$ & $\begin{array}{l}20 \\
11\end{array}$ & $\begin{array}{l}20 \\
12\end{array}$ & $\begin{array}{l}20 \\
13\end{array}$ & 2014 & 2015 & 2016 & 2017 & $\begin{array}{l}20 \\
18\end{array}$ \\
\hline Afonso & № de atendimentos & - & - & - & 174 & 211 & 268 & 160 & 43 \\
\hline Bezerra & Famílias atendidas & - & - & - & 114 & 112 & 94 & 23 & 22 \\
\hline \multirow{2}{*}{ Angicos } & № de atendimentos & - & - & - & - & - & - & - & - \\
\hline & Famílias atendidas & - & - & - & - & - & - & - & - \\
\hline \multirow{2}{*}{$\begin{array}{l}\text { Caiçara do } \\
\text { Rio do } \\
\text { Vento } \\
\end{array}$} & № de atendimentos & - & - & - & 30 & 78 & 23 & - & - \\
\hline & Famílias atendidas & - & - & - & 30 & 27 & 22 & - & - \\
\hline \multirow{2}{*}{$\begin{array}{c}\text { Fernando } \\
\text { Pedroza }\end{array}$} & № de atendimentos & - & - & - & 128 & 65 & 101 & - & - \\
\hline & Famílias atendidas & - & - & - & 62 & 34 & 37 & - & - \\
\hline \multirow{2}{*}{ Galinhos } & № de atendimentos & - & - & - & - & - & - & - & - \\
\hline & Famílias atendidas & - & - & - & - & - & - & - & - \\
\hline \multirow{2}{*}{ Guamaré } & № de atendimentos & - & - & - & - & - & - & - & - \\
\hline & Famílias atendidas & - & - & - & - & - & - & - & - \\
\hline \multirow{2}{*}{ Lajes } & № de atendimentos & - & - & - & 31 & 5 & 9 & - & - \\
\hline & Famílias atendidas & - & - & - & 20 & 4 & 9 & - & - \\
\hline \multirow{2}{*}{ Macau } & № de atendimentos & - & - & - & 14 & - & 2 & - & - \\
\hline & Famílias atendidas & - & - & - & 7 & - & 2 & - & - \\
\hline \multirow{2}{*}{ Pedra Preta } & № de atendimentos & 4 & 1 & - & 61 & 8 & 104 & - & - \\
\hline & Famílias atendidas & 1 & 1 & - & 48 & 5 & 35 & - & - \\
\hline Pedro & № de atendimentos & - & - & - & 68 & 117 & 19 & - & - \\
\hline Avelino & Famílias atendidas & - & - & - & 51 & 45 & 19 & - & - \\
\hline \multicolumn{2}{|c|}{ Total de no de atendimentos } & 4 & 1 & - & 506 & 484 & 526 & 160 & 43 \\
\hline \multicolumn{2}{|c|}{ Total de famílias atendidas } & 1 & 1 & - & 332 & 227 & 218 & 23 & 22 \\
\hline
\end{tabular}

Fonte: SEAD (2019). Elaboração dos autores.

Considerando que as ações de ATER desempenham importante papel por consistir no apoio aos agricultores familiares e suas organizações coletivas quanto à busca por soluções tecnológicas que despertem as potencialidades da agricultura familiar, a sua descontinuidade ou ruptura leva à fragilidade e ao não funcionamento do tripé organização coletiva-financiamento-assistência técnica. Entre outros fatores, o reduzido número de registros de atendimentos e de famílias atendidas no Território no período de 2011 a 2018 sugere um baixo nível de participação dos agricultores 
familiares em organizações coletivas, especialmente de cooperativas, e a pouca obtenção do crédito (que além dos valores reduzidos ainda predomina a modalidade investimento e muito pouco custeio).

Graficamente, nota-se a ausência dos registros de atendimentos de ATER e das famílias atendidas de 2011 a 2013, passando a ser registrados 506 atendimentos e 332 famílias atendidas em 2014, tendo uma leve queda para 484 atendimentos e 227 famílias atendidas em 2015, e um aumento para 526 atendimentos e 218 famílias atendidas no ano de 2016. Nos anos seguintes, 2017 e 2018 , os dados da pesquisa revelam uma queda brusca no número de atendimentos de ATER e de famílias assistidas. De atendimentos foram apenas 160 em 2017 e só 43 em 2018, e famílias atendidas foram 23 e 22, respectivamente, mostrando a descontinuidade das ações de ATER no Território, conforme gráfico 3.

Gráfico 3 - № de atendimentos e de famílias atendidas com ATER de 2011 a 2018, no Território Rural Sertão Central Cabugi e Litoral Norte.

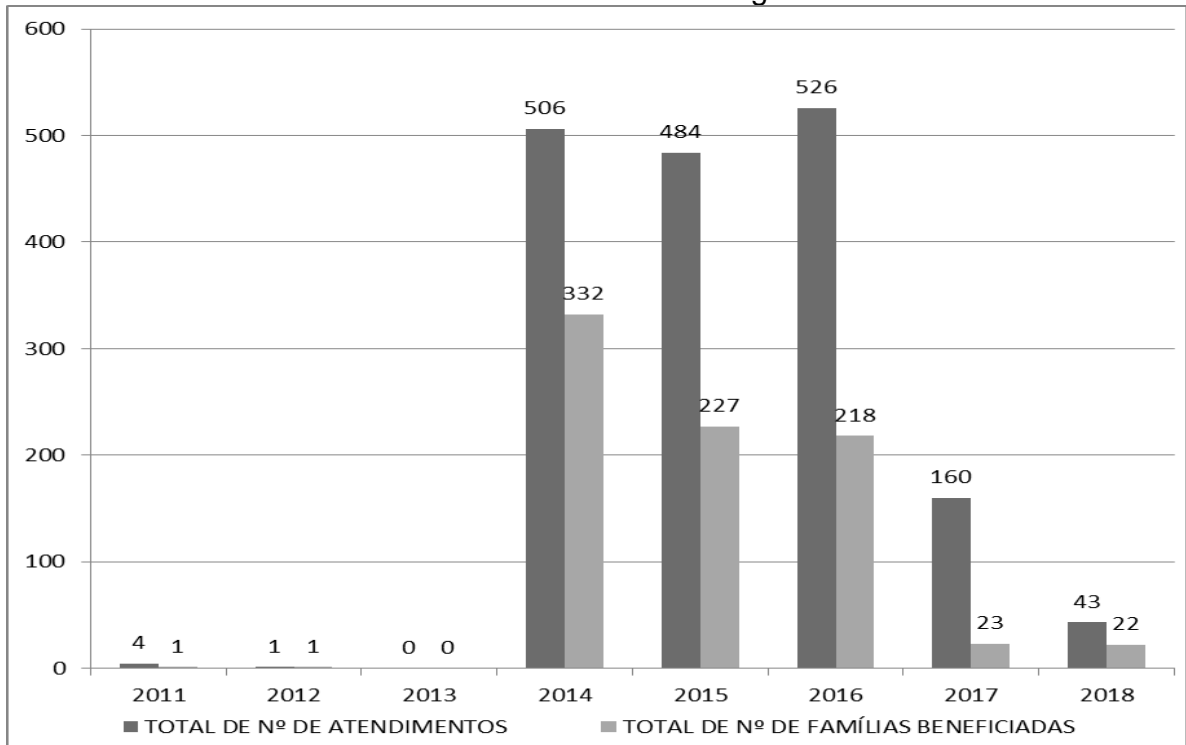

Fonte: SEAD (2019). Elaboração dos autores.

Enquanto política pública, as ações de ATER estiveram mais atreladas a soluções tecnológicas convencionais por meio de inovações técnica e institucional induzidas, na concepção de Hayami e Ruttan (1985), geralmente praticadas por organizações públicas e em apoio ao processo de modernização agrícola. Neste contexto, a ATER passou a focar na mudança técnica para o alcance de maiores níveis de produção e da produtividade visando alimentar complexos agroindustriais. A agricultura familiar foi parcialmente inserida e seguindo o modelo convencional.

Segundo os dados da pesquisa, os serviços de ATER no Território Rural Sertão Central Cabugi e Litoral Norte têm sido realizados por organizações públicas e privadas. Quanto às organizações públicas, é o Instituto de Assistência Técnica e Extensão Rural do Rio Grande do Norte (EMATER) quem atua no Território com ações de ATER em consonância com políticas agrícolas definidas pelos governos 
federal e estadual, com transferência de tecnologia e orientação gerencial. A partir da regulamentação da PNATER, em 2010, a EMATER vem se adaptando às orientações alternativas, a exemplo da concepção de "segunda ordem". Quanto à formação acadêmica dos agentes dos seis escritórios da EMATER, três são técnicos de nível médio na área agropecuária e três são engenheiros agrônomos com nível superior.

Os técnicos atuam nos escritórios da EMATER ou em locais cedidos pelas prefeituras, buscando promover a transferência de conhecimentos tecnológicos aos agricultores familiares. Com equipe técnica reduzida, eles atendem ao público através de rodízio nos municípios e tentam prestar apoio a algum técnico das prefeituras. O quadro 1 apresenta apenas os municípios e as EMATERs entrevistadas no período de 26 de agosto a 19 de setembro de 2016 .

Quadro 1 - Entidade pública que presta serviços de assistência técnica no Território Rural Sertão Central Cabugi e Litoral Norte, 2016.

\begin{tabular}{|c|c|c|c|c|}
\hline \multicolumn{5}{|c|}{ ENTIDADES PÚBLICAS } \\
\hline $\begin{array}{l}\text { ENTIDADE } \\
\text { DE ATER }\end{array}$ & MUNICÍPIO & $\begin{array}{l}\text { DESCRIÇÃO } \\
\text { DA ENTIDADE }\end{array}$ & $\begin{array}{c}\text { DESCRIÇÃO DO } \\
\text { AGENTE }\end{array}$ & $\begin{array}{l}\text { TEMPO DE } \\
\text { ATUAÇÃO }\end{array}$ \\
\hline EMATER & $\begin{array}{l}\text { Caiçara do Rio } \\
\text { do Vento }\end{array}$ & $\begin{array}{l}\text { Inst. De Assist. } \\
\text { Téc. E Ext. } \\
\text { Rural }\end{array}$ & $\begin{array}{l}\text { Técnico em } \\
\text { Agropecuária }\end{array}$ & 34 anos \\
\hline EMATER & Lajes & $\begin{array}{l}\text { Inst. de Assist. } \\
\text { Téc. E Ext. } \\
\text { Rural }\end{array}$ & $\begin{array}{l}\text { Engenheira } \\
\text { Agrônoma }\end{array}$ & 14 anos \\
\hline EMATER & Angicos & $\begin{array}{l}\text { Inst. de Assist. } \\
\text { Téc. E Ext. } \\
\text { Rural }\end{array}$ & $\begin{array}{l}\text { Engenheiro } \\
\text { Agrônomo }\end{array}$ & 15 anos \\
\hline EMATER & $\begin{array}{l}\text { Afonso } \\
\text { Bezerra }\end{array}$ & $\begin{array}{l}\text { Inst. de Assist. } \\
\text { Téc. E Ext. } \\
\text { Rural }\end{array}$ & $\begin{array}{l}\text { Engenheiro } \\
\text { Agrônomo }\end{array}$ & $\begin{array}{c}3 \text { anos e } 8 \\
\text { meses } \\
\text { (bolsista) }\end{array}$ \\
\hline EMATER & Pedra Preta & $\begin{array}{l}\text { Inst. de Assist. } \\
\text { Téc. E Ext. } \\
\text { Rural }\end{array}$ & $\begin{array}{l}\text { Técnico em } \\
\text { Agropecuária }\end{array}$ & $\begin{array}{c}3 \text { anos } \\
\text { (bolsista) }\end{array}$ \\
\hline EMATER & $\begin{array}{l}\text { Fernando } \\
\text { Pedroza }\end{array}$ & $\begin{array}{l}\text { Inst. de Assist. } \\
\text { Téc. E Ext. } \\
\text { Rural }\end{array}$ & $\begin{array}{l}\text { Técnico em } \\
\text { Agropecuária }\end{array}$ & $\begin{array}{c}6 \text { anos e } 4 \\
\text { meses }\end{array}$ \\
\hline
\end{tabular}

Fonte: Levantamento pesquisa de campo (2016). Elaboração dos autores.

As prefeituras municipais, de um modo geral, disponibilizam um técnico para a EMATER, como é o caso do município de Fernando Pedroza. Em outros municípios, como Pedro Avelino, Afonso Bezerra e Pedra Preta, a EMATER contrata profissional através de processo seletivo para o preenchimento de vagas, ao invés de realizar concurso público. Assim, as ações de ATER têm sido regidas pelos prazos de execução das chamadas públicas que, ao final do prazo, têm todas as atividades reduzidas ou encerradas. Apesar do esforço dos serviços de ATER, os atores e entidades denunciam a precariedade das ações de ATER pública:

Existem poucos profissionais, estruturas físicas comprometidas, escritórios alugados, outros fechados pelo não pagamento, falta de sinal de internet e telefonia fixa, o material de expediente é insuficiente. (...) Isso gera em nós um 
sentimento de desconfiança e distanciamento do público assistido, os agricultores familiares. A assistência técnica rural no Território Sertão Central Cabugi e Litoral Norte infelizmente não se consolidou e é difícil um bom trabalho devido à ausência e deficiência de infraestrutura e da frequente descontinuidade das políticas de ATER (Eng ${ }^{\circ}$ Agrônomo da EMATER, 56 anos, 12/10/2016).

Segundo os entrevistados, outros órgãos públicos assumem ações de ATER, a exemplo das secretarias municipais de agricultura, especialmente durante o preparo de solo e demais serviços básicos. Mas, de acordo com alguns entrevistados, essas ações complementares de ATER pública são insuficientes, pontuais, o que mantém serviços precários quanto aos atendimentos e às famílias de agricultores atendidas:

\begin{abstract}
Mesmo com a boa vontade dos técnicos, que são muito esforçados e atenciosos, tanto a EMATER como as prefeituras não têm nos ajudado muito, eles têm muitas dificuldades de ajudar a gente. A gente já é só, sem organização, aí é mais difícil ainda eles nos acompanhar e orientar na produção no campo, na criação dos animais e na venda da nossa produção. Tem sido muito difícil, mas não culpo eles não (Agricultor familiar de Angicos/RN, 62 anos, 28/10/2016).
\end{abstract}

Outros municípios do Território utilizam serviços de ATER privada ou de Organizações Não Governamentais (ONGs), a exemplo de Pedro Avelino, Galinhos, Guamaré e Angicos. O município de Angicos possui o serviço público e privado e, quanto à formação os técnicos que prestam serviços privados de ATER, possuem a mesma dos técnicos das entidades públicas, conforme se observa no quadro 2. São técnicos de ONGs que concorreram a editais do MDA com o Instituto Nacional de Colonização e Reforma Agrária (INCRA) e com a Secretaria de Estado de Assuntos Fundiários e Apoio à Reforma Agrária (SEARA) para ações específicas e não para uma ATER ampla para a agricultura familiar. 
Quadro 2 - Entidades privadas que prestam serviços de assistência técnica em 2016.

\begin{tabular}{|c|c|c|c|c|}
\hline \multicolumn{5}{|c|}{ ENTIDADES PRIVADAS } \\
\hline $\begin{array}{l}\text { ENTIDADE } \\
\text { DE ATER }\end{array}$ & MUNICÍPIO & $\begin{array}{c}\text { DESCRIÇÃO } \\
\text { DA } \\
\text { ENTIDADE }\end{array}$ & $\begin{array}{l}\text { DESCRIÇÃO } \\
\text { DO AGENTE }\end{array}$ & $\begin{array}{l}\text { TEMPO DE } \\
\text { ATUAÇÃO }\end{array}$ \\
\hline $\begin{array}{l}\text { Cooperativa } \\
\text { Terra Livre }\end{array}$ & $\begin{array}{l}\text { Pedro Avelino/ } \\
\text { Mossoró }\end{array}$ & $\begin{array}{l}\text { Cooperativa de } \\
\text { Assessoria } \\
\text { Técnica e Ger. } \\
\text { Desenvolviment } \\
\text { o Sustentável } \\
\text { Da Agricultura } \\
\text { Familiar }\end{array}$ & $\begin{array}{l}\text { Técnico em } \\
\text { Agropecuária }\end{array}$ & 14 anos \\
\hline PRODUTEC & $\begin{array}{l}\text { Galinhos e } \\
\text { Guamaré }\end{array}$ & $\begin{array}{l}\text { Associação de } \\
\text { Assistência a } \\
\text { produção do } \\
\text { produtor rural }\end{array}$ & $\begin{array}{l}\text { Técnico Agrícola } \\
\text { e Gestor } \\
\text { Ambiental }\end{array}$ & 4 anos \\
\hline ATECNORTE & Angicos & $\begin{array}{l}\text { Assistência } \\
\text { Técnica aos } \\
\text { produtores do } \\
\text { Nordeste }\end{array}$ & $\begin{array}{l}\text { Técnico em } \\
\text { Agropecuária }\end{array}$ & 8 anos \\
\hline
\end{tabular}

Fonte: Levantamento pesquisa de campo (2016). Elaboração dos autores.

A ATER privada atuou em menor escala até o ano de 2012 até o ano de 2015 com ações de assessoria das ONGs e organizações sindicais na tentativa de suprir as carências específicas de assistência técnica pública. No entanto, a ATER privada não logrou o êxito esperado, sendo ela no Território estimulada, a partir de então, pela Universidade numa ação ampla de articulação:

A chegada da Universidade no Território em 2014 foi um dos pontos mais positivos que tivemos. Foi o momento mais intenso, onde a Universidade conseguiu articular e estimular para acontecer as ações de ATER pública e fez a gente sentir aproximar o conhecimento popular com metodologia mais cientifica e técnica para buscar soluções para a agricultura familiar. Por outro lado, entidades financeiras disponibilizam recurso de crédito do PRONAF, mas a não interação com a ATER e a alta inadimplência tem reduzido as operações. E, para nós, sem crédito não existe ATER, além de parte dos agentes de crédito criar desprezo, provocando distância dos agricultores (M. F. S: sindicalista, STTR, 34 anos, 04/11/2016).

Neste caso, para a intervenção de ATER acontecer, a adequação sóciotécnica no Território deveria se dar em dois momentos: na estruturação e organização coletiva dos agricultores familiares e ATER via formações. Na primeira, como as unidades familiares rurais possuem uma organização autogestionária, o conhecimento de gestão nesse tipo precisa ser garantido. No segundo, o aprendizado precisa se adaptar às situações concretas que surgem, daí a ideia de "adaptação sócio-técnica". Essa adequação está relacionada ao conhecimento científico e tecnológico, já incorporado por um lado, e, por outro lado, é preciso pensar nos aspectos socioeconômicos que constituem a relação saber e sociedade. De acordo com um dos entrevistados: 
A concepção científica e tecnológica difundida pelas ações de ATER com o estímulo da Universidade considerou as particularidades dos empreendimentos e a sabedoria do agricultor familiar do Território. Isso fez com que a adequação sócio-técnica fosse entendida por nós como o que se coloca entre o que funciona para modelos convencionais, tentando adaptá-los para as necessidades dos agricultores familiares, e não o inverso. (Engenheiro agrônomo da EMATER, 42 anos, $11 / 11 / 2016)$.

Nesse sentido, a adequação sócio-técnica estimulada pela Universidade nas ações de ATER no Território Rural Sertão Central Cabugi e Litoral Norte, e afirmada na pesquisa durante a construção do Diagrama de Venn, pode ser definida como uma articulação que procurou aliar a construção científica derivada das pesquisas para aplicá-las às realidades da agricultura familiar, como a perspectiva novelty production, ou concepção de "segunda ordem".

\section{CONSIDERAÇÕES FINAIS}

A organização dos Territórios rurais possui suas fortalezas e fragilidades, e o grande dilema está em analisá-las com a mesma lógica dos empreendimentos convencionais: competitividade, quantidade de produção, investimentos etc. Já quando inseridos na agricultura familiar, são consideradas concepções alternativas, e de "segunda ordem", a exemplo da diversificação e da sustentabilidade. É neste sentido que Dagnino e Novaes (2007) propõem a adequação sócio-técnica, dizendo que ela supre a necessidade de criação de um "substrato cognitivo" que auxilie alternativas a competirem de forma mais igualitária às convencionais.

Assim, falar da ATER é encarar as especificidades locais, suas implicações econômicas, sociais e culturais e seus desafios organizacionais. Todos podem se beneficiar dos "velhos" modelos, mas precisam se reinventar para dar conta dessas particularidades, daí a necessidade da adequação sócio-técnica. A pesquisa constatou que os modelos convencionais não se encaixam perfeitamente, e sem caráter científico e técnico os agricultores familiares não conseguirão se apropriar das velhas lições e adaptá-las. E as ações de ATER têm papel fundamental nesse processo, principalmente quanto à sua continuidade para obtenção da mudança.

De acordo com a PNATER, o desenvolvimento rural deve adotar processos alternativos de desenvolvimento endógeno, com práticas participativas e métodos sustentáveis, considerando a questão social e ambiental. Porém, a insuficiência dos financiamentos aos agricultores familiares reflete a ausência e deficiência de estrutura de organização coletiva e de produção que levam a atividades precárias. Esse cenário limita a atuação dos técnicos e reproduz um círculo vicioso, pois em atividades precárias as ações de ATER nem sempre são suficientes para garantir a efetividade dessa política.

A pesquisa constatou que no Território as ações de ATER pública e privada desenvolvidas a partir de órgãos como a EMATER, prefeituras, ONGs e sindicatos rurais se mostraram precárias e insuficientes. No entanto, a participação da Universidade aconteceu no sentido de estimular as ações de ATER numa articulação para fortalecê-las, pois no Território ainda existe pouca integração entre ATER, organização coletiva e crédito rural, contribuindo para limitar o processo de adequação socio-técnica. Por outro lado, a pesquisa revelou uma necessidade urgente para 0 atendimento da demanda dos empreendimentos, no sentido de encontrar soluções tecnológicas para os agricultores familiares e suas organizações coletivas, além de maior diversificação das cadeias produtivas e dos investimentos 
para construir infraestrutura de produção econômica. A pesquisa constatou, ainda, o pouco uso dos recursos de custeio e a concentração dos investimentos numa única cadeia, o que revela uma precária infraestrutura e pouca diversificação econômica, na qual o crédito se mostra fragmentado, não atendendo as necessidades dos agricultores familiares.

Este trabalho conclui que, especialmente para o Território Sertão Central Cabugi e Litoral Norte é difícil integrar o tripé organização-crédito rural-ATER e há limites para o processo de adequação sócio-técnica. Assim, se faz necessário assumir novas formas de enxergar a produção, o consumo e a organização da agricultura familiar, considerando estratégias de co-produção, labour-driven intensification e novelty production. Essas estratégias possuem em seus fundamentos a organização coletiva e a diversificação e buscam criar soluções tecnológicas alternativas no sentido da sustentabilidade e da concepção de "segunda ordem", que por vezes vão de encontro com os fundamentos de modelos convencionais da modernização.

Enfim, a adequação sócio-técnica contribui para uma nova ATER, pois propõe um processo educativo continuado, com ações mais participativas. Dessa forma, a nova concepção de ATER no Território Sertão Central Cabugi e Litoral Norte deve contribuir para reforçar a interação entre a organização coletiva e o crédito, por meio de práticas sustentáveis e diversificadas, mas possíveis de serem implantadas, pois precisam nascer do saber e da experiência do agricultor familiar.

\section{AGRADECIMENTOS}

Este trabalho faz parte de um conjunto de pesquisas desenvolvidas no âmbito da agricultura familiar, e agradecemos ao Conselho Nacional de Desenvolvimento Científico e Tecnológico (CNPq), pelo auxílio concedido através da Chamada Encomendas COSAE MDA 2013 (APQ).

\section{REFERÊNCIAS}

BRASIL. Território Rural Sertão Central Cabugi e Litoral Norte (RN). Brasília: NEDET/UERN, mapa, colorido. Escala 1:550.000, 2016.

BRUNORI, G.; RAND, S.; PROOST, J.; BARJOLLE, D.; GRANBERG, L.; DOCKES, A. C. Towards a conceptual framework for agricultural and rural innovation policies. Projeto Insight. Report on the conceptual framework (WP1), 2008. 27 p. Disponível em: www.insightproject.net/files/poster_conceptual_frameworks_DBO.pdf. Acesso em: 12 mar. 2019.

CAPORAL, F. R.; RAMOS, L. Da extensão rural convencional à extensão rural para o desenvolvimento sustentável: enfrentar Desafios para Romper a Inércia. Texto para discussão, Brasília, set. 2006. Disponível em: http://agroecologia.pbworks.com/f/Artigo-Caporal-Ladjane-Vers\%C3\%A3oFinalParaCircular-27-09-06.pdf. Acesso em: 05 jan. 2020.

COELHO, A. L. P. Adequação sócio-técnica e tecnologia social: os desafios na organização do trabalho da Associação de Reciclagem e Proteção Ambiental (ARPA). In: VII JORNADA INTERNACIONAL DE POLÍTICAS PÚBLICAS (VII JOINPP), 2015, São Luís, MA. Anais... São Luís: Universidade Federal do Maranhão, 2015. p.11. 
DAGNINO, R. "Ciência e tecnologia para a cidadania" ou adequação sociotécnica com o povo?. In: Tecnologia Social: contribuições conceituais e metodológicas [online]. Campina Grande: EDUEPB, p. 89-112, 2014.

DAGNINO, R.; NOVAES, H. T. Adequação sócio-técnica na agenda das políticas Públicas. In: II COLÓQUIO INTERNACIONAL CÁTEDRA UNESCO-UNISINOS (V ENCONTRO DE ESTUDOS SOBRE O MUNDO DO TRABALHO), 2005, São Leopoldo, Anais... São Leopoldo: Universidade do Vale do Rio dos Sinos, 2005.

FEENBERG, A. Teoria Crítica da Tecnologia: um panorama. In: Tailor-Made BioTechnologies, v.1, n.1, abri./maio, 2005. Disponível em: http://www.sfu.ca/ andrewf/feenberg_luci.htm. Acesso em: 01 set. 2019.

HAYAMI, Y.; RUTTAN, V. W. Agricultural Development: an international perspective. Baltimore: J. Hopkins, 1985.

INSTITUTO BRASILEIRO DE GEOGRAFIA E ESTATÍSTICA - IBGE. Cidades. Disponível em:http://www.cidades.ibge.gov.br. Acesso em: 22 ago. 2014.

INSTITUTO BRASILEIRO DE GEOGRAFIA E ESTATÍSTICA - IBGE. Pesquisa de Informações Básicas Municipais 2017. Disponível em: https://metadados.ibge.gov.br/consulta/estatisticos/operacoes-estatisticas. Acesso em: 12 jul. 2018.

KATZ, J.; CIBOTTI, R. Marco de referencia para un programa de investigación en ciencia y tecnología en América Latina. Buenos Aires: Cepal, 1976.

KNICKEL, K., G. BRUNORI, S. RAND, J. PROOST. Towards a Better Conceptual Framework for Innovation Processes in Agriculture and Rural Development: From Linear Models to Systemic Approaches. The Journal of Agricultural Education and Extension, v. 15, p. 131-146, 2009. Disponível em: https://doi.org/10.1080/13892240902909064. Acesso em: 01 set. 2019.

KUMMER, L. Metodologia participativa no meio rural: uma visão interdisciplinar. Conceitos, ferramentas e vivências. Salvador: GTZ, 2007.

MOSCHITZ, H.; ROEP D.; BRUNORI G.; TISENKOPFS T. Learning and Innovation Networks for Sustainable Agriculture: Processes of Co-evolution, Joint Reflection and Facilitation. The Journal of Agricultural Education and Extension, v. 21, n. 1, p. 1-11, 2015. Disponível em: https://doi.org/10.1080/1389224X.2014.991111. Acesso em: 01 set. 2019.

NOVAES, A. G. Logística e gerenciamento da cadeia de distribuição. Rio de Janeiro: Elsevier, 2007.

NUNES, E. M.; SILVA, V. M.; SÁ, V. C. Assistência Técnica e Extensão Rural (ATER): formação e conhecimentos para a agricultura familiar do Rio Grande do Norte. Redes, Santa Cruz do Sul, v. 25, p. 458-482, 2020. 
NUNES, E. M.; GONDIM, M. F. R.; SILVA, M. R. F. Identidade e reestruturação produtiva nos Territórios Açu-Mossoró e Sertão do Apodi, no Rio Grande do Norte. Estudos Sociedade e Agricultura, v.27, n,1 p.137-166, 2019.

NUNES, E. M.; TÔRRES, F. L.; SILVA, M. R. F.; SÁ, V. C.; GODEIRO-NUNES, K. F. Dinamização econômica e agricultura familiar: limites e desafios do apoio a projetos de infraestrutura (PROINF) em territórios rurais do Nordeste. Revista de Economia e Sociologia Rural, v. 53, n. 3, p.529-54, 2015a.

NUNES, E. M.; ARAUJO, I. J.; FRANÇA, A. R. M.; LIMA, J. S. S. de; MEDEIROS, L. S. Microcrédito, Infraestrutura e Desenvolvimento Rural: o Agroamigo Investimento e Custeio na agricultura familiar de Territórios do Rio Grande do Norte. Revista Econômica do Nordeste, v.46, p.53-69, 2015b.

NUNES, E. M.; FRANÇA, A. R. M.; LIMA, J. S. S.; MEDEIROS, L. S. Novidades (Novelty) na Agricultura Familiar e sua associação com a agroecologia na produção de hortifrutigranjeiros no Território Sertão do Apodi (RN). Redes, Santa Cruz do Sul, v.23, n,1 p. 213-236, 2018.

OLIVEIRA, D.; GAZOLLA, M.; SCHNEIDER, S. Produzindo novidades na agricultura familiar: agregação de valor e agroecologia para o desenvolvimento rural. Cadernos de Ciência \& Tecnologia, v.28, p.17-49, 2011.

OOSTINDIE, H. BROEKHUIZEN, R. von. The dinamic of novelty production. In: PLOEG, J. D. van der and MARSDEN, T. (Eds.) Unfolding Webs: The dynamics of regional rural development. Assen: Van Gorgum, p. 262, 2008.

PAIVA, R. M. Modernização e dualismo tecnológico na agricultura. Rio de Janeiro: Pesquisa e Planejamento Econômico, v. 1, n. 2, p. 171-234, 1971.

PLOEG, J. D. van der. The New Pensantries: struggles for autonomy and sustainability in an era of empire and globalization. Earthscan, Sterling VA, London, 2008.

PLOEG, J. D. van der.; WISKERKE, J. S. C. (Eds.) Seeds of transition: essays on novelty production, niches and regimes in agriculture. Assen: Van Gorcun, 2004.

SECRETARIA ESPECIAL DE AGRICULTURA FAMILIAR E DO DESENVOLVIMENTO AGRÁRIO. Painel de Políticas da Sead, Brasília, 2019. Disponível em: http://nead.mda.gov.br/politica/localidade/. Acesso em 15 nov. 2019.

Serviço Nacional de Aprendizagem do Cooperativismo no Estado do Rio Grande do Norte - SESCOOP/RN. Disponível em: http://sescooprn.coop.br. Acesso em: 29 jul. 2019.

SILVA, C. R. F. E.; SILVA, M. R. F.; NUNES, E. M. A operacionalização do Programa de Aquisição de Alimentos (PAA), na modalidade Compra com Doação Simultânea (CDS) no território Açu-Mossoró (RN). Revista Extendere, v. 5, p. 148165, jul./dez. 2017. Disponível em: http://periodicos.uern.br/index.php/extendere/article/view/3573. Acesso em: 01 set. 2019. 
STUVIER, M.; WISKERKE, J. The VEL and VANLA Enviromental Co-operatives as a Niche for Sustainable Development. In: WISKERKE, J. S. C.; PLOEG, J. D. van der. In: PLOEG, J. D. van der and WISKERKE, J. S. C. (Eds.) Seeds of transition: essays on novelty production, niches and regimes in agriculture. Assen: Van Gorcun, p. 119-148, 2004. 